\title{
Environmental magnetic field in a Neonatal Intensive Care Unit. A relevant verification
}

\author{
Janet Carvajal de la Osa, B.S. and MSc $c^{a}$, Junior Santana González, Engineer ${ }^{b}$, \\ Michael Herrera Galán, Engineer and MScc, Alaen Sánchez Grau, Engineer and MSc ${ }^{d}$ \\ and C. Ignat Pérez Almirall, M.D. and Engineera
}

\begin{abstract}
Preterm infants are born with immature organs, thus affecting the immune system. Electromagnetic fields influence melatonin production with low exposure levels. These infants require medical equipment $24 / 7$ to recover, so they are constantly exposed to magnetic fields during their stay in the Intensive Care Unit. Our objective was to measure magnetic field levels generated around each incubator using a gauss meter and compare our results to the 2010 recommendations by the International Commission on Non-Ionizing Radiation Protection and the IEC 60601-1-2:2004 standard by the International Electrotechnical Commission (IEC). Among 11 hospitalized newborn infants, radiation was found within the recommended limits, but there was electromagnetic interference resulting from medical equipment layout problems in the unit. Key words: magnetic fields, melatonin, equipment and supplies.
\end{abstract}

http: / / dx.doi.org/10.5546/ aap.2020.eng.e246

d. Center for Research Development, and Production "Grito de Baire" (Centro de Investigación, Desarrollo y Producción "Grito de Baire," CIDPGB), Union of Cuban Military Industries - Ministry of Revolutionary Armed Forces (Unión de Industrias Militares de CubaMinisterio de las Fuerzas Armadas Revolucionarias, UIM-MINFAR), Havana, Cuba.

E-mail address: Janet Carvajal de la Osa, B.S.: janetco@ automatica.cujae.edu.cu

Funding:

None.

Conflict of interest: None.

Received: 2-8-2019 Accepted: 10-19-2019

th in a hospital's intensive care unit is characterized by a delicate process of adaptation from intrauterine to extrauterino life. ${ }^{1}$ These infants are born when their organs are still immature, so they tend to develop all types of diseases. In this situation, the immune system is committed to a constant fight to defend the body, so it is in a disadvantaged position against any external alteration. ${ }^{2-4}$

Non-ionizing radiation refers to radiation that does not carry enough energy to break ionic bonds. Low-frequency electromagnetic fields (EMFs) are a combination of electric and magnetic waves that travel simultaneously in the $0-300 \mathrm{~Hz}$ range and are usually expressed as magnetic flux density (B) or magnetic field strength $(\mathrm{H})$ using the Tesla unit (T). ${ }^{5}$ Units may be converted as follows: $1 \mathrm{~T}=104 \mathrm{G}$ or $0.1 \mu \mathrm{T}=1 \mathrm{mG}$ and $1 \mathrm{~A} / \mathrm{m}=1.26 \mu \mathrm{T}$. $^{6}$

Medical equipment is a source of electromagnetic radiation and EMFs are considered harmful by the World Health Organization (WHO). ${ }^{7}$ In this stage, due to the amount of medical equipment required by newborns infants for their recovery, they are exposed to uncontrolled radiation 24/7 while hospitalized.

In 1993, Russel Reiter and Jo Robinson published their book Melatonin, ${ }^{9}$ which included a theory explaining that a reduced melatonin secretion, induced by EMFs, may lead to an increased incidence of cancer by reducing the immune and antioxidant defense provided by melatonin. This hypothesis was corroborated by several scientists and, in 2002, the team led by N. Cherry ${ }^{9}$ demonstrated the ability of electromagnetic radiation to reduce circulating melatonin levels.

\section{MELATONIN AND ELECTROMAGNETIC FIELD IN A NEONATAL INTENSIVE CARE UNIT \\ Melatonin}

The pineal gland is a midline brain structure that converts serotonin into melatonin during the night. ${ }^{10}$ Melatonin production is an essential signal for the internal synchronization of endocrine and non-endocrine rhythms, such as the sleep/wake cycle. ${ }^{11-13}$ It is also a crucial part of the immune and antioxidant system 
because it assists in the destruction of free radicals. $^{14}$

Exposure to low-frequency EMFs suppresses melatonin production because they have the ability of visible light to pervade the environment with their energy, thus impairing pineal gland performance to produce and secrete melatonin into the bloodstream. ${ }^{15}$ During gestation, the fetus perceives, through the umbilical cord, their mother's emotions and circadian rhythm, thus secreting melatonin. Secretion levels are detected as of 24 weeks of gestation and gradually increase until birth. ${ }^{16,17}$

Newborn infants use this melatonin in the maturation of circadian rhythms in their first 72 hours of life because melatonin production is so imperceptible in the first week that the brain does not recognize it. Perceptible levels only start to be noticed 8 weeks after birth, increasing its production up to $50 \%$ of adult levels ${ }^{18}$ and stabilizing at about 2-3 months old and 3-5 months old in term ${ }^{18-20}$ and preterm ${ }^{16}$ newborn infants.

At the neonatal intensive care unit (NICU), lights are regulated, but they cannot be turned off during the night, as is the case of air conditioning and medical equipment used for newborn infant vital support, thus becoming the main sources of low-frequency EMFs. Melatonin production levels are subject to the light/ dark cycle which, at the NICU, cannot be imposed. Therefore, the little melatonin production is altered, as well as the possibility of a faster recovery for an alreadycompromised immune system, thus creating the conditions for the development of opportunistic diseases, ${ }^{21}$ leukemia, ${ }^{22}$ and cancer ${ }^{20}$ in the long term.

\section{Evidence of the effects of magnetic fields on fetuses and newborn infants}

Since 2006, effects caused by exposure to EMFs have been observed in fetuses and newborn infants. They occur in the setting of long-term, sustained low doses. Human studies have demonstrated that gestational exposure is a window for the development of mutant blood cells that are only activated after birth and turn into leukemia cells. ${ }^{23,24}$ Genotoxicity affecting deoxyribonucleic acid (DNA) creates a bond with the development of different cancers. ${ }^{25}$ Damage occurs on the structure of selected brain cells and molecules; ${ }^{26}$ the physiological and reproductive parameters of adults whose mothers were exposed to EMFs during pregnancy have also shown damage. ${ }^{27}$
Animal studies have demonstrated effects on the increase of serum iron levels ${ }^{28}$ and high levels of cell death resulting from elevated endocrine indicators. ${ }^{3}$

Sources of fetal and neonatal exposure include computer (laptop) ${ }^{29}$ and mobile phone use during pregnancy and neonatal incubators with high radiation levels. ${ }^{22,30}$

\section{Electromagnetic fields and medical equipment}

IEC 60601-1-2 standard ${ }^{31}$ establishes that medical equipment should operate in a magnetic field of $3 \mathrm{~A} / \mathrm{m}=3.78 \mu \mathrm{T}$, while the recommendations by the International Commission on Non-Ionizing Radiation Protection (ICNIRP) ${ }^{6}$ indicate that people should not remain in a room where radiation exceeds $2 \times 10^{-4} \mathrm{~T}=200 \mu \mathrm{T}$. Expected levels inside an incubator are below $10 \mathrm{mG}=1 \mu \mathrm{T}$; however, values up to $88.4 \mathrm{mG}=8.84 \mu \mathrm{T}$ have been observed in normal incubators and up to $357 \mathrm{mG}=35.7 \mu \mathrm{T}$ in transport incubators. ${ }^{32}$

The EMF decreases as the distance from the source increases. Therefore, an increased mattress thickness reduces EMF exposure levels. The material of the incubator frame also plays a major role. With plastic frames, the increase does not exceed $0.1 \mathrm{mG}=0.01 \mu \mathrm{T} ;{ }^{32}$ however, if they are made of iron, it may reach $500 \mathrm{mG}=50 \mu \mathrm{T}$. ${ }^{32}$

\section{Experience}

The objective of this study was to measure lowfrequency EMFs generated in the environment of a NICU and their influence on incubators so as to verify whether magnetic induction levels, as established by the ICNIRP 2010 guidelines, and the values defined by the IEC standard for electromagnetic compatibility were within recommended limits to ensure newborn infant protection.

The study was conducted in the third and fourth week of April 2018 at the level III NICU of Hospital Ramón González Coro, a provincial referral facility for newborn infants with a birth weight of less than $1500 \mathrm{~g}$. The NICU had 6 cubicles for the hospitalization of patients and beds were distributed depending on the treatment each newborn required.

Magnetic fields were measured using a PCE-G28 gauss meter. Table 1 describes the technical specifications provided by the manufacturer. 


\section{Methodology for measurements}

1. The fields radiated by incubators were measured by positioning the sensor perpendicular to the incubator's outer walls and measuring the radiation that reached the 4 sides with the sensor placed at $1.0 \mathrm{~m}$ above ground level. It was rotated clockwise (from left to right) so as to recreate the same conditions for all measurements. This task was repeated for 5 days in a row, twice a day (morning and afternoon). Such measurement procedure was developed based on the bibliography and introducing specific features in relation to our objective.

2. Values were averaged.

3. Then, values were compared to those recommended by the ICNIRP 2010 guidelines for the general public and the electromagnetic interference limits set by the IEC, and subsequently plotted.

TABLE1.Technical specifications of the PCE-G28 gauss meter

\begin{tabular}{ll}
\hline Data shown & Current measurement \\
\hline Range & 0 to $20 \mu \mathrm{T} / 0$ to $200 \mu \mathrm{T} / 0$ to $2000 \mu \mathrm{T}$ \\
Resolution & $0.01 / 0.1 / 1 \mu \mathrm{T}$ (depending on range) \\
Accuracy & $\pm 4 \%+3 \mathrm{~d}$ (in range $20 \mu \mathrm{T}$ ) \\
& $\pm 5 \%+3 \mathrm{~d}$ (in range $200 \mu \mathrm{T})$ \\
& $\pm 10 \%+5 \mathrm{~d}$ (in range $2000 \mu \mathrm{T})$ \\
Frequency & $30-300 \mathrm{~Hz}$ \\
Display & LCD screen \\
Weight & $470 \mathrm{~g}$ \\
Power & $9 \mathrm{~V}$ battery
\end{tabular}

d: digits.

\section{Data collection}

Preterm infants born before 37 weeks of gestation or with a birth weight of less than $2500 \mathrm{~g}$ and term infants with a birth weight of less than $5000 \mathrm{~g}$ were hospitalized at this NICU. These infants stayed at the NICU approximately 5 to 15 days if their condition was not very severe and up to several months if they had a very severe disease.

At the time of the study, 11 newborn infants were hospitalized and distributed among the cubicles as shown in Table 2, which also shows collected physical and technological data and magnetic field levels measured at each incubator. It was observed that cubicles D and E were smaller and medical equipment items were jumbled together, so the distance between them was measured to verify, based on the formula described in the IEC standard, that electromagnetic non-interference requirements between medical equipment items were met in terms of distance.

\section{Significant aspects and recommendations}

Values were measured outside the incubators due to biosafety concerns and in compliance with the epidemiological regulations of the Cuban Ministry of Health (MINSAP). The comparison of the average values with the recommendations by the ICNIRP and the IEC standard is shown in Figure 1, and it is observed that they are not exceeded.

The precautionary principle is applied when there is a high level of scientific uncertainty and a need to take measures against potentially

TABLE 2. Average measurement values and population characteristics and technology per bed

\begin{tabular}{|c|c|c|c|c|c|c|}
\hline Cubicle & Equipment & Br (average) & Weight (g) & Gestational age (weeks) & Length of stay (days) & Equipment \\
\hline \multirow{4}{*}{ THERAPY B } & Incubator 1 & $0.66 \mu \mathrm{T}$ & 2800 & 38.4 & 10 & MPP \\
\hline & Incubator 2 & $0.87 \mu \mathrm{T}$ & 1920 & 35 & 21 & MPP; V \\
\hline & Incubator 3 & $0.82 \mu \mathrm{T}$ & 1475 & 34.3 & 15 & V; MPP; IP \\
\hline & Incubator 4 & $0.30 \mu \mathrm{T}$ & - & - & - & Out of service \\
\hline THERAPY C & Incubator 1 & $0.74 \mu \mathrm{T}$ & 1480 & 29 & 30 & V; IP; 2MPP; 2PP \\
\hline \multirow[t]{3}{*}{ THERAPY D } & Incubator 1 & $0.47 \mu \mathrm{T}$ & 1585 & 32 & 15 & $\mathrm{MPP}$ \\
\hline & Incubator 2 & $0.78 \mu \mathrm{T}$ & 1680 & 32.4 & 15 & $\mathrm{MPP}$ \\
\hline & Incubator 3 & $0.76 \mu \mathrm{T}$ & 1620 & 32.4 & 15 & $\mathrm{MPP}$ \\
\hline \multirow[t]{5}{*}{ THERAPY E } & Warmer 1 & $0.45 \mu \mathrm{T}$ & 3600 & 40 & 5 & - \\
\hline & Warmer 2 & $0.70 \mu \mathrm{T}$ & 3125 & 36.2 & 5 & - \\
\hline & Warmer 3 & $0.47 \mu \mathrm{T}$ & 3480 & 41 & 5 & - \\
\hline & Warmer 4 & $0.34 \mu \mathrm{T}$ & - & - & - & Out of service \\
\hline & Warmer 5 & $0.31 \mu \mathrm{T}$ & - & - & - & Out of service \\
\hline THERAPY F & Incubator 1 & $0.13 \mu \mathrm{T}$ & - & - & - & Out of service \\
\hline THERAPY H & Incubator 1 & $0.67 \mu \mathrm{T}$ & 1240 & 30.3 & 45 & APP; V; MSD; IP; PP \\
\hline
\end{tabular}

Br: flux density; MPP: monitor of physiological parameters; V: ventilator; IP: infusion pump; PP: perfusion pump;

MSD: medical suction device. 
severe risks without waiting for the outcomes of further scientific investigations. ${ }^{33}$ For this reason, respecting reference levels will warrant the respect of basic restrictions.

The following factors help to limit radiations: 1) incident field parameters; 2 ) characteristics of exposed body (size, internal and external geometry, and tissue dielectric properties); and 3) effects of electrical ground and reflection of other objects on the field close to the exposed body. For this reason, the dosimetry for non-ionizing radiation limits was defined by correlating the effects of temperature on the body, i.e., absorbed energy transformed into thermal energy.

Based on this principle, and to limit nonionizing radiation in the low-frequency range, the ICNIRP adopted a value of $1000 \mu \mathrm{T}$ for $50 / 60 \mathrm{~Hz}$ for occupational exposure with a safety margin large enough to prevent the stimulation effects of contact-induced currents under all possible conditions. They adopted the same criterion for reference levels for the general public and reduced them to a fifth, i.e., $200 \mu \mathrm{T}$, thus preventing indirect adverse effects for more than $90 \%$ of exposed individuals, especially considering children. ${ }^{6}$

Although measured values were far below the standard, it is worth paying attention to other matters, such as the situation in cubicle $\mathrm{C}$, where there were too many equipment items around the incubator, which may have caused the resulting value. Or, for example, cubicles $\mathrm{B}$ and $\mathrm{H}$, where incubators had been in use for 30 years and, even though they still stood in for comfortable fetal uterine conditions, they may have lost their electromagnetic compatibility feature.

Based on this criterion, this medical equipment should be replaced.

In addition, electromagnetic interference is one of the most important factors leading to increased EMF levels. This is because it always increases the existing field due to its additive capacity. Based on the studies done on this matter, it may cause either malfunctioning without any major complications or life-threatening conditions, or even lead to misdiagnosis due to false positive results. ${ }^{34}$ For this reason, medical equipment compatibility, the distance between equipment items to prevent interference with one another, and environmental values for operation have been standardized by the IEC. Reviewing the cubicles, it was observed that in cubicles D and E some incubators were too close to one another so, since electromagnetic interference was suspected, distance was measured to implement the formula for the minimum distance for non-interference established by the IEC standard: $\mathrm{D}=1,2 \sqrt{\mathrm{P}}(1)$, so as to determine if suspicions were true. Based on estimations, it was observed that this type of incubator should be more than $1.2 \mathrm{~m}$ away from

FIGURE 1. Chart to compare the study measurements to the standard values established by the International Electrotechnical Commission (IEC) and those recommended by the International Commission on Non-Ionizing Radiation Protection (ICNIRP)

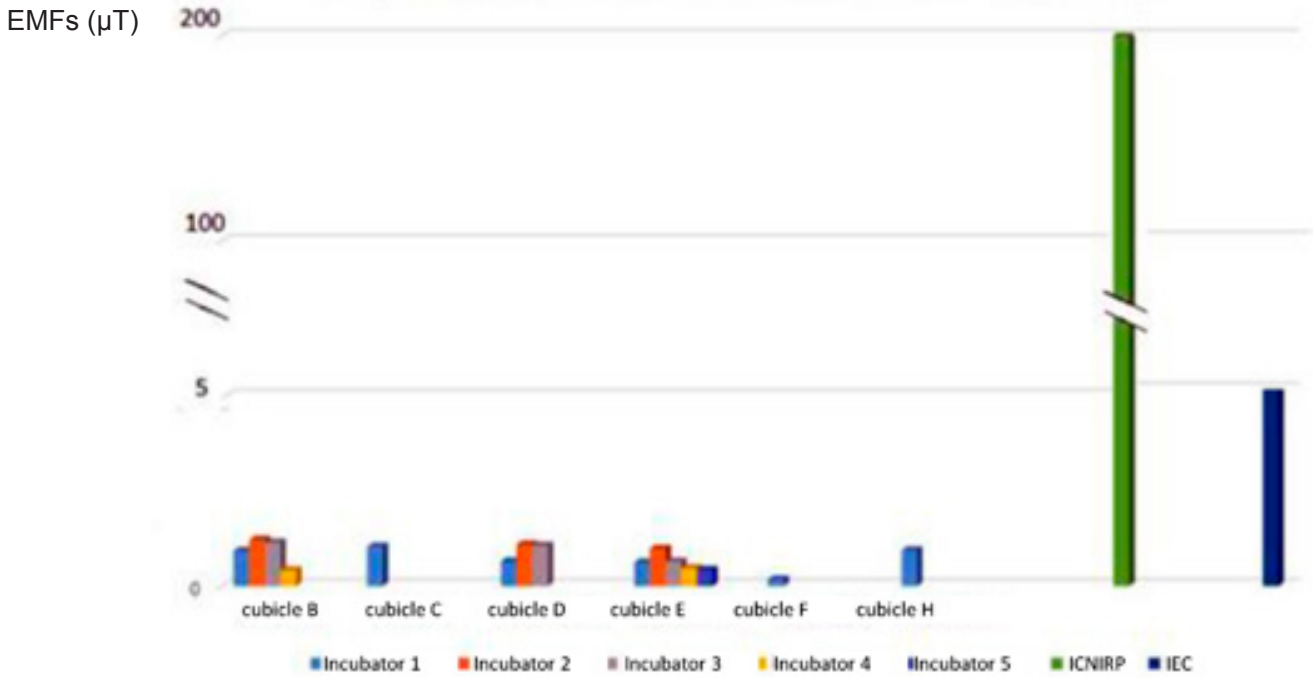

EMFs: electromagnetic fields; IEC: International Electrotechnical Commission; ICNIRP: International Commission on Non-Ionizing Radiation Protection. 
any equipment, which would reduce radiation values by $20 \%$, whereas in cubicle $\mathrm{D}$, warmers should be at $1 \mathrm{~m}$ from one another. When observing the values for this cubicle, the $0.70 \mu \mathrm{T}$ measurement was determined between 2 sources, so an infant in that position is exposed to higher values and a greater risk.

To eliminate such interference, it is recommended to place medical equipment at a distance equal to or higher than estimated limits.

All measurements were within standard and expected values. This does not mean that this area should not be supervised because the effects on neonatal melatonin in incubators as of $0.2 \mu \mathrm{T}^{35}$ up to $10 \mu \mathrm{T}$ have been reported; in addition, they start affecting the heart and cause chest angina and fibrillation, ${ }^{30}$ and even heart attack when reaching $20 \mu \mathrm{T} .{ }^{22,32}$

A strict surveillance of medical equipment distance is recommended because interference is imperceptible to the eye and increases radiation levels in the electromagnetic environment.

\section{CONCLUSIONS}

According to measurements, the lowfrequency magnetic field was within the limits established by the ICNIRP 2010 guidelines and the IEC. Although values did not exceed those recommended by the ICNIRP and the IEC, it is worth noting that patients at the NICU received non-ionizing radiation $24 / 7$, so it was very important to maintain the precautionary principle. These verifications should be extended to other facilities where these health care services are offered, because it is important to know the potential effects on future infant development.

\section{REFERENCES}

1. Herrera Aguirre AG, Rodríguez Tapia J, Suárez Aceves R, Hernández Bautista VM. El sistema inmune neonatal y su relación con la infección. Alerg e InmunolPediátr. 2013; 22(3):101-13.

2. Rellan Rodríguez S, Garcia De Ribera C, Aragón García MP. El recién nacido prematuro. In: Junta Directiva de la Sociedad Española de Neonatología. Protocolos Diagnóstico Terapeúticos de la AEP: Neonatología. 2.da ed. Madrid:SEN; 2008; 8:68-77.

3. Johansson O. Disturbance of the immune system by electromagnetic fields-A potentially underlying cause for cellular damage and tissue repair reduction which could lead to disease and impairment. Pathophysiology. 2009; 16(2-3):157-77.

4. Alessandrini Garaboa N, Sarmiento Portal Y, Marquez Concepción Y, Portal Miranda ME, et al. El recién nacido pretérmino con infección de inicio precoz. Rev Ciencias Médicas. 2015; 19(6):1014-27.

5. Belyaev I, Dean A, Eger H, Hubmann G, et al. EUROPAEM EMF Guideline 2016 for the prevention, diagnosis and treatment of EMF-related health problems and illnesses. Rev Environ Health. 2016; 31(3):363-97.

6. International Commission on Non-Ionizing Radiation Protection. Guidelines for limiting exposure to time-varying electric and magnetic fields (1 HZ to $100 \mathrm{kHZ}$ ). Health Phys. 2010; 99(6):818-36.

7. OrganizaciónMundialdelaSalud.Estableciendoundiálogo sobre los riesgos de los campos electromagneticos. Ginebra: OMS; 2005: 42. [Accessed on: October 22 nd 2019]. Available at: https: / / www.who.int/ peh-emf/ publications / emf _ handbook spanish.pdf $\mathrm{u}$ a=T.

8. Reiter R, Robinson J. Melatonin. New York: Bantam Books; 1996. [Accessed on: October 22 $\left.{ }^{\text {nd }}, 2019\right]$. Available at: https://www.pengu in random house.com/ books / 140286/melatonin-by-russel-j-reiter-phd-and-jorobinson/9780553574845/.

9. Cherry NJ. EMF/EMR reduces melatonin in animals and people. 2002. [Accessed on: October 22 ${ }^{\text {nd }}, 2019$ ]. Available at: https:// research archive .lincoln. ac.nz/bitstream/ handle/10182/3906/90_b1_EMR_Reduces_Melatonin_ in_Animals_and_People.pdf? sequence $=1$ \&isAllowed $=\mathrm{y}$.

10. López-Muñoz F, Marín F, Álamo C. El devenir histórico de la glándula pineal: II. De sede del alma a órgano neuroendocrino. Rev Neurol. 2010; 50(2):117-25.

11. Acuña Castroviejo D. Informe científico sobre el efecto de los campos electromagnéticos en el sistema endocrino humano y patologías asociadas. Granada: Universidad de Granada; 2006. [Accessed on:October 22 $\left.{ }^{\text {nd }}, 2019\right]$. Availableat:https: / / maruxahernando.typepad.com/mi_weblog/2013/01/ nforme-cient\%C3\%ADfico-sobre-el-efecto-de-los-camposelectromagn $\%$ C3\% A9ticos-en-el-sistema-endocrinohumano-y-patolog\%C3\%ADas-asociadas-1.html.

12. Peñuela Epalza ME, Páez Jiménez DA, Castro Cantillo LC, Harvey OrtegaJC, etal.Prevalencia deinsomnioen adultos de 18 a 60 años deedad y exposición a camposelectromagnéticos enhogares deBarranquilla, Colombia. Biomédica.2015;35(Supl 2):120-9.

13. Jiménez-Rubio G, Solís-Chagoyán H, Domínguez-Alonso A, Benítez-King G. Alteraciones del ciclo circadiano en las enfermedades psiquiátricas: papel sincronizador de la melatonina en el ciclo sueño-vigilia y la polaridad neuronal. Salud Ment. 2011; 34 (2): 167-73.

14. Consales C, Merla C, Marino C, Benassi B. Electromagnetic fields, oxidative stress, and neurodegeneration. Int Cell Biol. 2012; 2012:683897.

15. Srinivasan V, Pandi-Perumal SR, Brzezinski A, Bhatnagar KP, etal.Melatonin,immunefunctionand cancer. Recent Pat Endocr Metab Immune Drug Discov. 2011; 5(2):109-23, 2011.

16. Marseglia L, Manti S, D’Angelo G, Gitto E, et al. Melatonin for the newborn. J Pediatr Neonat Individual Med. 2014; 3(2):e030232.

17. Bruni O, Alonso-Alconada D, Besag F, Biran V, et al. Current role of melatonin in pediatric neurology: Clinical recommendations. Eur J Paediatr Neurol. 2015;19(2):122-33.

18. Biran V, Phan Duy A, Decobert F, Bednarek N, et al. Is melatonin ready to be used in preterm infants as a neuro protectant. Dev Med Child Neurol. 2014; 56(8):717-23.

19. Paprocka J, Kijonka M, Rzepka B, Sokół M. Melatonin in Hypoxic-Ischemic Brain Injury in Term and Preterm Babies. Int J Endocrinol. 2019; 2019:9626715.

20. Muñoz-Hoyos A, Bonillo-Perales A, Ávila-Villegas R, González-Ripoll M, et al. Melatonin levels during the first week of life and their relation with the antioxidant response in the perinatal period. Neonatology. 2007; 92(3):209-16.

21. Pin Arboledas G, Merino Andreu M, De la Calle Cabrera T, Hidalgo Vicario MI, et al. Consenso sobre el uso de melatonina en niños y adolescentes con dificultades para iniciar el sueño*. An Pediatr (Barc). 2014; 81(5):328.e1-9. 
22. Söderberg KC, Naumburg E, Anger G, Cnattingius S, et al. Childhood Leukemia and Magnetic Fields in Infant Incubators. Epidemiology. 2002; 13(1):45-9.

23. Kheifets L, Afifi A, Monroe J, Swanson J. Exploring exposure-response for magnetic fields and childhood leukemia. J Expo Sci Environ Epidemiol. 2011; 21(6):625-33.

24. Zhao L, Liu X, Wang C, Yan K, et al. Magnetic fields exposure and childhood leukemia risk: a meta-analysis based on 11,699 cases and 13,194 controls. Leuk Res. 2014; 38(3):269-74.

25. Udroiu I. Genotoxic properties of extremely low frequency electromagnetic fields. In: Guiliani L, Soffritti M(eds.). Nonthermal effects and mechanisms of interaction between electromagnetic fields and living mater. Bologna: Mattioli; 2010.Págs.123-34.

26. Markov M, Grigoriev Y. Protect children from EMF. Electromagn Biol Med. 2015; 34(3):251-6.

27. Paparella C, Pavesi A, Provenzal O, Ombrella A, et al. Infertilidd masculina. Exposicion laboral a factores ambientales y su efecto sobre la calidad seminal. Rev Urug Med Int. 2017; 2(2):10-21.

28. Söker S, Sert C, Deniz M, Ayazc E, et al. The effect of extremely low frequency magnetic field on heart tissue iron density. J Clin Exp Invest. 2011; 2(2):144-48.

29. Bellieni CV, Pinto I, Bogi A, Zoppetti N, et al. Exposure to Electromagnetic Fields From Laptop Use of "Laptop"
Computers. Arch Environ Occup Health. 2012; 67(1):31-6.

30. Bellieni CV, Acampa M, Maffei M, Maffei S, et al. Electromagnetic fields produced by incubators influence heart rate variability in newborns. Arch Dis Child Fetal Neonatal Ed. 2008; 93(4):F298-301.

31. International Electrotechnical Commission. IEC 60601-1-2 Medical electrical equipment. Part 1-2: General requirements for safety - Collateral standard: Electromagnetic compatibility - Requirements and tests. Geneva: IEC; 2004.

32. Bellieni CV, Nardi V, Buonocore G, Di Fabio S, et al. Electromagnetic fields in neonatal incubators: the reasons for an alert. J Matern Fetal Neonatal Med. 2018; 32(4):695-9.

33. Ohliger T. La política de medio ambiente: principios generales y marco básico. Fichas temáticas sobre la Unión Europea, Parlamento Europeo. 2019. [Accesse don: October $\left.22^{\text {nd }}, 2019\right]$. Available at: http: / / www.europarl.europa.eu / factsheets/es/ sheet/71/la-politica-de-medio-ambienteprincipios-generales-y-marco-basico.

34. Luca C, Ciorap R, Andritoi D. Influence of electromagnetic fields on medical devices used in the thermoregulations. Acta Electroteh. 2018; 59(4):277-80.

35. Bellieni CV, Tei M, Lacoponi F, Tatarano ML. Is newborn melatonin production influenced by magnetic fields produced by incubators? Early Hum Dev. 2012; 88(8):707-10. 